\title{
Effectiveness of Teaching Aids in Medical Education
}

\author{
Deepa Sanjeev Nair ${ }^{1 *}$, Madhura Yogesh Bedekar ${ }^{1}$, Meena Jitendra Agrawal ${ }^{1}$ and Anagha Madan Gupte ${ }^{2}$ \\ ${ }^{1}$ Department of Physiology, MIMER Medical College, Talegaon (D), Pune, India \\ ${ }^{2}$ School of Business Maharashtra Institute of Technology, Pune, India
}

\begin{abstract}
Background: Invention of computer and internet has revolutionized each \& every field. Technology enhanced learning is very popular among students including medical students. Teaching aids have become an integral part of medical college teaching. The study was conducted to find out the effectiveness of teaching aids in medical college teaching and compare different teaching aid methods.

Method: Study was conducted in the practical class of I MBBS. Students were divided in to three batches designated as A, B \& C. Pre- test using multiple choice questions (MCQ) was conducted to analyze the knowledge level of the students. Different teaching aids were used for each batch .Chalk-board method, Power point presentation (PPT) with chalk-board, and PPT were the teaching aids used. Post- test with same MCQ was conducted. Effectiveness of different teaching aid was done by comparing pre-test and post-test marks using paired ' $t$ ' test. Different teaching aids were compared using ' $Z$ ' test.

Result. Comparison between chalk-board with chalk-board plus PPT showed that gain in knowledge was more when chalk- board and PPT were combined and the difference was statistically significant $(\mathrm{p}<0.05)$. Chalk-board and PPT, when compared, there was no statistically significant difference between the two methods even though gain in knowledge was slightly higher when PPT was used. PPT and combine use of PPT plus chalk-board didn't show any statically significant difference when compared, but the gain in knowledge was higher with combination of PPT and chalk-board method.

Conclusion: Chalk- board method, when combined with PPT is a better teaching aid method than individual method when used alone. The reason for not getting the statically significant difference could be due to the less no. of MCQ in pre-test and post-test. Each teaching aid has got its own advantages and disadvantages. Teaching aid used should be appropriate to the topic
\end{abstract}

Keywords: Teaching Aid, Chalk- Board Method, Power Point Presentation

\section{Introduction}

As they say, the change is inevitable. Invention of computer and internet has revolutionized each and every field. As the computer gained popularity, technology enhanced learning also became popular. Use of teaching aids is very common in present day teaching. Scenario in the medical colleges also is not different. Collins English dictionary defines teaching aid as 'any device, object or machine used by a teacher to clarify or enliven a subject [1]. Various teaching aid methods include the traditional chalk and board method as well as the modern methods like over head projectors (OHP), PowerPoint presentations (PPT) and other audio visual aids. Power Point presentations are very effective in seminars and large group teaching. There is a view that traditional black board teaching method provides strong student teacher interaction but its effectiveness declines as the no. of student in the class increases [2]. Is it true? Or the power point presentations are replacing the conventional chalk and board method even when the no. of students is not so large. Nowadays there is too much of use of power point presentation especially among youngsters. The dependency on this method is so great to the extent that in some class rooms there is not even provision for chalk and board. The modern teaching aids- Are they teacher's aid or teaching aid? Is the modern power point presentation is beneficial to the students?

Previous studies on the same subject showed the following finding. Seth V et al, in their study suggested that medical students preferred PowerPoint presentations over chalk and board [3] where as Vamshi KT et al suggested that students preferred the traditional chalk and talk over microsoft power point presentation [4]. The study conducted by Baxi $\mathrm{SN}$ et al suggested that equal no. of students' preferred black board based or multimedia based lectures [5].

The results were different in different studies Most of the study conducted were using questionnaire and these were student's perspective. Our study is an attempt to analyze the effectiveness of teaching aids in medical colleges in not so large groups, where teacher student interaction is possible.

The study the effectiveness of teaching aids in medical college students and compare different teaching aid methods 


\section{Material and Method}

The following activity was done in the usual practical class of first MBBS. Three groups of students each were selected (Group A, Group B \& Group C). A topic for practical demonstration, which was new to them, was selected. Topic selected was perimetry.

The sequence was

1. Pre - test consisting of 10 Multiple Choice Questions (MCQ)

Time given was 10 minutes for answering the MCQ

Separate answer sheets were given to each student

Answer sheets were collected after 10 minutes.

2. Briefing of practical aspect of perimetry along with necessary theory information

3. Practical demonstration

4. Post test with the same MCQ

MCQ- Each correct answer carried 1 mark \& no negative marking for wrong answer.

For Briefing: For Group A- Briefing of the practical was done by Chalk - Board method

Group B- PPT with LCD projector combined with chalkboard is used

For Group C- PPT with LCD Projector was used

Statistical Analysis Results of pre- test \& post test of each teaching aid is compared with paired ' $t$ ' test. . Effectiveness of different teaching aids was compared with ' $\mathrm{Z}$ 'test

\section{Result}

I. Comparison between before training and after training for

1. Chalk-Board method: Knowledge level of the students before and after training was compared. Paired ' $t$ ' test was applied. It was observed that mean marks obtained by the students after training increased significantly as compared to mean marks before training. Mean difference in marks was 3.97, which was highly significant statistically. $(\mathrm{p}<0.001)$ (Table-1)

2. Chalk- Board +PPT with LCD projector method: Knowledge level of the students before and after training was compared. Paired ' $t$ ' test was applied It was observed that mean marks obtained by the students after training increased significantly as compared to mean marks before training. Mean difference in the marks, 4.68, was statistically highly significant. $(\mathrm{p}<0.001)$ ( Table-1)

3. PPT method: Knowledge level of the students before and after training was compared. Paired t' test was applied.
The difference between the knowledge level before training and after training by using PPT method was highly significant. Mean difference in the marks was 4.36 $(\mathrm{p}<0.001)$ ( Table-3)

II. Comparison between Chalk-Board and PPT with chalk \& Board Gain in knowledge was calculated by taking the difference between marks obtained before and after training in case of both the method- chalkboard (3.97) and PPT with chalk-board (4.68). ' $\mathrm{Z}$ ' test was applied to test the mean increase in marks by both the methods. Though the training by both the methods improved the knowledge of the students, the training with the help of PPT with chalk- board produced better result. The difference between increases in marks was significant, means difference 0.71 , and was statistically significant. $(\mathrm{p}<0.05)$ (Table-2)

III. Comparison between Chalk-board \& PPT The training by only chalk-board and then training by PPT method was compared. Difference between marks obtained before and after training in case of both the methods was calculated. ' $Z$ ' test was applied to test the mean increase in marks by both the methods. The average difference between increases in marks of the two methods were similar. There is no statistically significant difference between these two methods. Impact of these two methods is similar. Even if the average increase by chalk-board + PPT method (4.36) is more than only chalk-board method (3.97), the difference is not statistically significant. Difference in marks $(0.39)$ was statistically not significant $(\mathrm{p}>0.05)$ ( Table-4).

IV. Comparison between PPT and Chalk-board + PPT Gain in knowledge was found by taking the difference between marks obtained before and after training in case of both the methods. ' $Z$ ' test was applied to test the mean increase in marks by both the methods. . The average difference between increases in marks of the two methods is similar. There is no statistically significance between these two methods. ( $p>0.05)$ Chalk-board + PPT\& PPT are giving similar result. But the increase in marks in PPT + Chalk- board training method is s higher (4.67 as compared to 4.36) even though it is not statistically significant (Table-5)

\section{Discussion}

In our study we observed that gain in knowledge occurred with all three teaching methods, that is, chalk - board teaching, PPT and combination of Chalk-board and PPT. The increase in the marks was statistically significant in all three teaching methods. [Table 1, \& 3]. When we compared chalk-board with PPT plus chalk -board, we observed that gain in knowledge was more with the combined use 
Table 1: Comparison between before training and after training for Use of chalk-Board method Chalk- Board +Power point presentation (PPT) using LCD projector .

\begin{tabular}{|c|c|c|c|c|}
\hline \multirow{2}{*}{ Parameters } & \multicolumn{2}{|c|}{ Chalk-Board method } & \multicolumn{2}{|c|}{ Chalk - Board + PPT } \\
\hline & Before training & After training & Before training & After training \\
\hline $\begin{array}{l}\text { No. of students } \\
\text { evaluated }\end{array}$ & 38 & 38 & 34 & 34 \\
\hline $\begin{array}{l}\text { Mean marks } \\
\text { obtained }\end{array}$ & 3.13 & 7.10 & 3.32 & 8.0 \\
\hline SD & \multicolumn{2}{|c|}{1.53} & \multicolumn{2}{|c|}{\begin{tabular}{l|l}
1.17 & 0.98 \\
\end{tabular}} \\
\hline $\begin{array}{l}\text { Comparison } \\
\text { between before and } \\
\text { after training }\end{array}$ & \multicolumn{2}{|c|}{$\begin{array}{l}\text { Paired't' test was applied. } \\
\text { Mean difference }=3.97 \\
t=15.13 ; \text { d.f. }=37 ; p<0.001 \\
\text { The difference between the knowledge level before } \\
\text { training and after training by using chalk-board } \\
\text { method is highly significant. }\end{array}$} & \multicolumn{2}{|c|}{$\begin{array}{l}\text { Paired't' test was applied. } \\
\text { Mean difference }=4.68 \\
\mathrm{t}=23.23 ; \mathrm{d} . \mathrm{f} .=33 ; \mathrm{p}<0.001 \\
\text { The difference between the knowledge level } \\
\text { before training and after training by using Chalk- } \\
\text { board+PPT is highly significant. }\end{array}$} \\
\hline
\end{tabular}

Table 2: Comparison between Chalk-Board and PPT with chalk \& Board

\begin{tabular}{|l|l|l|} 
& Chalk-Board method & PPT with chalk \& Board \\
\hline Mean increase in marks & 3.97 & 4.68 \\
\hline Comparison & 1.62 & 1.17 \\
\hline
\end{tabular}

Table 3: Comparison between before training and after training for PPT .

\begin{tabular}{|l|l|l|}
\hline Parameters & PPT & After training \\
\hline & Before training & 39 \\
\hline No. of students evaluated & 39 & 7.74 \\
\hline SD & 3.38 & 1.07 \\
\hline $\begin{array}{l}\text { Comparison between before and after } \\
\text { training } \\
\text { Paired't' test was applied. }\end{array}$ & 1.77 & $\begin{array}{l}\text { Mean difference }=4.36 ; t=13.22 ; \text { d.f. }=38 ; p<0.001 ; \text { The difference between the } \\
\text { knowledge level before training and after training by using PPT method is highly } \\
\text { significant. }\end{array}$ \\
\hline
\end{tabular}

Table 4: Comparison between chalk-board method \& PPT method.

\begin{tabular}{|l|l|l|} 
& Chalk-Board method & PPT method \\
\hline Mean increase in marks & 3.97 & 4.36 \\
\hline Comparison & 1.62 & 2.05 \\
\hline & $\begin{array}{l}\text { Mean difference }=0.39 ; Z=0.91 ; p>0.05, \text { The difference } \\
\text { is not statistically significant. }\end{array}$ & \\
\hline
\end{tabular}

Table 5: Comparison between PPT+ Chalk - Board \& PPT.

\begin{tabular}{|l|l|l|}
\hline & PPT + chalk \& Board & PPT method \\
\hline SD & 4.67 & 4.36 \\
\hline Comparison & 1.17 & 2.05 \\
\hline & $\begin{array}{l}\text { Mean difference }=0.31 ; Z=0.79 ; p>0.05, \text { The difference is not statistically } \\
\text { significant. }\end{array}$ \\
\hline
\end{tabular}


of PPT \& chalk-board and the difference was statistically significant $(\mathrm{p}<0.05)$ [Table-2].

The comparison between chalk-board with PPT showed that even though mean difference was more in PPT method, it was not statistically significant ( $>0.05$ ) [table-4]. As we compared the gain in knowledge of PPT with chalk-board plus PPT, we observed that increase in the marks after training was more in the latter compared to the former, but the increase was not statistically significant [Table-5].

Baxi et al conducted a study using questionnaire method in a medical college and they arrived at the conclusion that overall preference of the students was distributed equally between black board teaching and multimedia teaching [5]. Another study conducted by Sheikh S T arrived in a conclusion that medical student preferred a combination of teaching aid - chalk \&board and power point presentation incorporating animation. The above study also used questionnaire method. Hall R suggested the importance of application of technology to medical education. The study was conducted in 1969 [6].

In our study when we compared the chalk-board method with PPT, we observed a higher increase in the marks in PPT compared to chalk-board even though it was not statistically significant. Topic chosen by us was 'perimetry'. Here the three dimensional understanding of the instrument was required which cannot be done with chalk-board method. That might be the reason of slightly better result with PPT compared to chalk-board. Comparison between PPT \& chalk-board plus PPT didn't show statically significant difference, even though gain in knowledge was slightly higher in PPT plus chalk- board. The reason of not getting statically significant increase might be the no. of multiple choice questions used in pre test and post test. Only 10 questions were there as the topic was small. Studies with more no. of MCQ may produce a statistically significant increase in favour of combination method ( PPT plus chalk-board) The results of our study suggest that the combination method, Chalk- board plus PPT, as the best teaching method. This underlines the fact that we cannot ignore the importance of chalk-board method even in the present technology era. We can display a figure on a PPT presentation, but how to draw that figure can be better explained with chalk-board. Each teaching aid has got its own advantage and disadvantages. So selecting the teaching aid appropriate to the topic is very important. Combination of different teaching aids will be the best method to understand various concepts in medical subjects

\section{Conclusion}

Technology enhanced learning has gained popularity in medical colleges. Use of teaching aids is very common in present day teaching. In our study we compared the different teaching aid methods, chalk-board method, PPT and combination of chalk-board with PPT. Teaching aid used should be appropriate to the topic. Our study suggested that chalk-board and PPT when combined together resulted in better understanding of the topic in I MBBS students. It is true that we should adopt the new techniques which have benefit, at the same time we should preserve old methods which has got advantage and cannot be replaced by any other method.

\section{Acknowledgement}

Physiology department, MIMER Medical College, Talegaon (D), Pune, India

\section{References}

1. Collins English Dictionary- Complete \& Unabridged 12th edition 2014, Harper Collin Publication

2. Shaikh S T. Teaching learning aids in medical education: The student perspective. Int J Clin Surg adv 2015; 3 (1): 32-37.

3. Seth V, Upadhyaya P, Ahmed M, Moghe V. Powerpoint or Chalk and talk: Perception of medical students versus dental students in a medical college in India. Adv. Med Educ Pract 2010; 1: 11-16.

4. Vamshi K T, Datta V M, Kishan Y S S, Aditya V, Bhanuprakash G. Comparative study on the teaching effectiveness of chalk and talk and Microsoft Power Point presentation from student perspective. Int J Pharm Pharm Sci 2012; 4 (1) 191-193.

5. Baxi S N, Shah C J, Parmar R D, Parmar D, Tripathi C B. Student perception towards different teaching aids in a medical college. African Journal of health professions education 2009; 1(1):15.

6. Hall R. Audio Visual aids in medical education. BrMed J 1969; 4 (5674) 40-41

*Corresponding author:

Dr. Deepa Sanjeev Nair, 'Bhairavi', Bungalow No.7, Sector-26, A.D.C, Behind L.I.C Training Centre, Pradhikaran, Nigdi, Pune, India, PIN- 411044 Phone: +91 9326026733

Email: drdeepasnair@rediffmail.com

Date of Submission : 15.02.2076

Date of Acceptance : 23.02.2017

Financial or other Competing Interests: None.

Date of Publication : 27.02.2017 